\title{
Comment on "Optimizing the Delivery of Inhaled Medication for Respiratory Patients: The Role of Valved Holding Chambers"
}

\author{
Michael T. Newhouse ${ }^{1}$ and Israel Amirav $\mathbb{D}^{2}$ \\ ${ }^{1}$ Firestone Institute for Respiratory Health, St. Joseph's Hospital, McMaster University, Hamilton, ON, Canada \\ ${ }^{2}$ Pediatric Department, University of Alberta, Edmonton, AB T6G2C6, Canada \\ Correspondence should be addressed to Israel Amirav; amirav@ualberta.ca
}

Received 29 December 2018; Accepted 27 June 2019; Published 25 July 2019

Academic Editor: Massimo Pistolesi

Copyright ( 2019 Michael T. Newhouse and Israel Amirav. This is an open access article distributed under the Creative Commons Attribution License, which permits unrestricted use, distribution, and reproduction in any medium, provided the original work is properly cited.

McIvor et al. [1] recently suggested that regulatory authorities (e.g., US Food and Drug Administration (FDA), Health Canada, and Japan's Pharmaceuticals and Medical Devices Agency) should harmonize and follow the European Medicines Agency (EMA) recommendation that valved holding chambers (VHCs) are not interchangeable.

We endorse their position but think that their recommendation that devices meet "minimal quality and performance standards" (based only on ex vivo studies that characterise MDI aerosol particle characteristics and dose output) lacks scientific rigor.

We suggest that there are many additional and clinically important factors related to how these devices are used by patients in vivo under real-life conditions that are not, and cannot be, accounted for by laboratory studies such as that of McIvor et al. and previous similar reports [2], since they fail to take into account "real-world" conditions.

We would like to draw attention to three important yet neglected "real-world" aspects that are not considered when comparing VHC and mask aerosol delivery ex vivo. These relate to compliance, inspiratory flow, and mask dead space.

With respect to adherence, compliance, and acceptance, rejection of masks has long been known to be a major factor in real-life aerosol therapy of infants and young children [3]. Yet, none of the regulatory bodies takes this critical factor into account. The only mask that specifically addresses this issue is the soft and very low dead-space SootherMask ${ }^{\mathrm{TM}}$, specifically designed to accept the child's own pacifier [4], thereby providing a much more familiar, comfortable, and acceptable device for these children. Furthermore, SootherMask $^{\mathrm{TM}}$ has been shown to be the only evidence-based method for consistently achieving bronchodilator aerosol therapy to infants while asleep [5]. Previous studies were not able to accomplish this [6], a particularly problematic issue as many children are frequently awakened by asthma exacerbations and require treatment at night.

Another important factor is the inspiratory flow velocity (IFV). Low IFV has been shown to facilitate reduced upper respiratory tract aerosol deposition and considerably increased aerosol delivery to the lungs of about $40 \%$, of even relatively large particles (MMAD $6.5 \mu \mathrm{m}$ ), if the IFV is in the order of about $12 \mathrm{~L} / \mathrm{min}$ [7]. This will, of course, depend not only on the resistance to flow but also on patient effort. In this regard, patients can benefit from inspiratory flow feedback provided by means of a reed or whistle, yet there are many different such devices and this factor has never been considered in the in vitro studies. For example, most commonly used VHC audio feedback devices use a reed to alert patients at an IFV of 30-60 L/min. By contrast, the newer InspiraChamber ${ }^{\circledR}$ whistle alerts the patient at $15-$ $30 \mathrm{~L} / \mathrm{min}$, thus potentially reducing the turbulence-related throat dose, thereby augmenting the lung dose.

Additionally, the extremely important question of mask dead space used in small children is not taken into account in regulatory conclusions. Recent studies have shown considerable differences in dead space with various masks [8]. Clearly, if the volume of the mask dead space is not taken into account and is significantly larger with one brand of 
mask or if greater pressure is required to achieve a seal [9], thus frightening the child, with even the best in vitro studies showing differences in aerosol delivery, the results may be clinically irrelevant!

In our opinion, using only laboratory criteria to determine superiority of any MDI + VHC combination over another fails to take into account important "real-world" device and patient-related clinical issues. These are determined by pMDI and $\mathrm{VHC} /$ mask design features that individually or in combination will surely have an effect that is equal to or greater than the recent laboratory-demonstrated differences in various MDI + VHC combinations [2] that, as a result, have led to totally unwarranted clinical conclusions [1].

\section{Conflicts of Interest}

Both authors have patent rights to aerosol devices. Dr Newhouse is Chief Medical Officer for InspiRx pharma, a division of Nostrum Pharma, Somerset, NJ. He holds several patents related to aerosol delivery masks and MDI + VHC as well as DPI systems for treating asthma, COPD, and other pulmonary diseases (WO2012173992A1, US 6470882B1, 6470882, 8119016, D689602, D685085, D686725; pending: 2012/0318261, 2012/0318265).

\section{Authors' Contributions}

Both authors were involved in conception, design, and drafting of the manuscript.

\section{References}

[1] R. A. McIvor, H. M. Devlin, and A. Kaplan, "Optimizing the delivery of inhaled medication for respiratory patients: the role of valved holding chambers," Canadian Respiratory Journal, vol. 2018, Article ID 5076259, 8 pages, 2018.

[2] J. Mitchell and M. B. Dolovich, "Clinically relevant test methods to establish in vitro equivalence for spacers and valved holding chambers used with pressurized metered dose inhalers (pMDIs)," Journal of Aerosol Medicine and Pulmonary Drug Delivery, vol. 25, no. 4, pp. 217-242, 2012.

[3] M. L. Everard, "Trying to deliver aerosols to upset children is a thankless task," Archives of Disease in Childhood, vol. 82, no. 5, pp. $428 \mathrm{a}-428,2000$.

[4] I. Amirav, A. S. Luder, A. Halamish et al., "Design of aerosol face masks for children using computerized 3D face analysis," Journal of Aerosol Medicine and Pulmonary Drug Delivery, vol. 27, no. 4, pp. 272-278, 2014.

[5] I. Amirav, M. T. Newhouse, A. Luder, A. Halamish, H. Omar, and M. Gorenberg, "Feasibility of aerosol drug delivery to sleeping infants: a prospective observational study," BMJ Open, vol. 4, no. 3, article e004124, 2014.

[6] J. Esposito-Festen, H. Ijsselstijn, W. Hop, F. van Vliet, J. de Jongste, and H. Tiddens, "Aerosol therapy by pressured metered-dose inhaler-spacer in sleeping young children," Chest, vol. 130, no. 2, pp. 487-492, 2006.

[7] A. R. Clark, C. B. Chambers, D. Muir, M. T. Newhouse, S. Paboojian, and C. Schuler, "The effect of biphasic inhalation profiles on the deposition and clearance of coarse $(6.5 \mu \mathrm{m})$ bolus aerosols," Journal of Aerosol Medicine, vol. 20, no. 1, pp. 75-82, 2007.
[8] I. Amirav, A. S. Luder, A. Halamish, C. Marzuk, M. Daitzchman, and M. T. Newhouse, "Computerized deadspace volume measurement of face masks applied to simulated faces," Respiratory Care, vol. 60, no. 9, pp. 1247-1251, 2015.

[9] I. Amirav, A. Halamish, M. Gorenberg, H. Omar, and M. T. Newhouse, "More realistic face model surface improves relevance of pediatric in-vitro aerosol studies," PLoS One, vol. 10, no. 6, Article ID e0128538, 2015. 


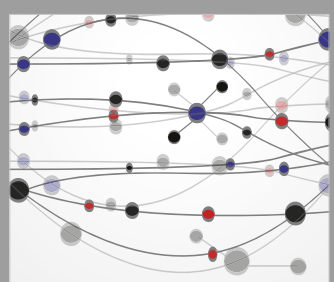

The Scientific World Journal
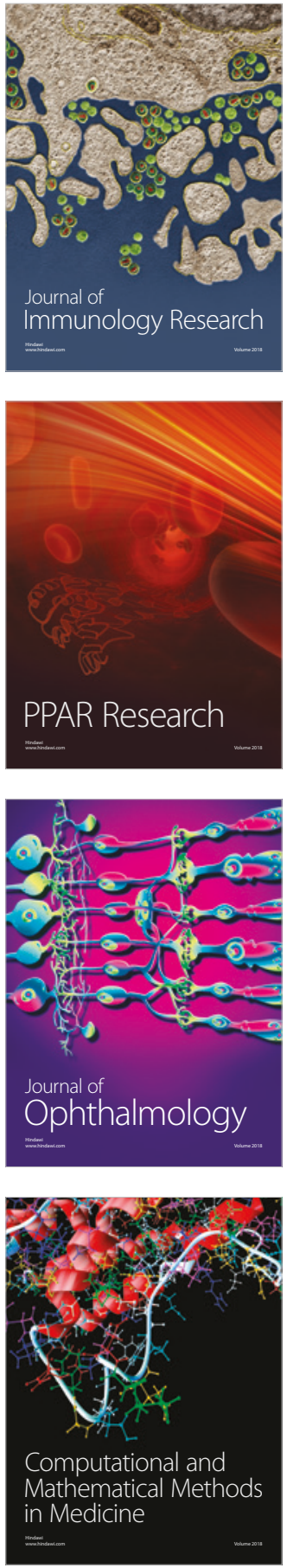

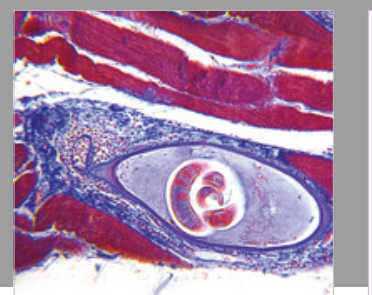

Gastroenterology Research and Practice

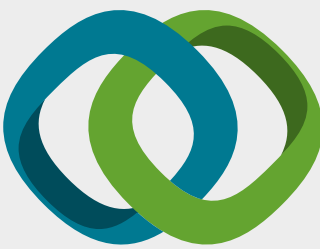

\section{Hindawi}

Submit your manuscripts at

www.hindawi.com
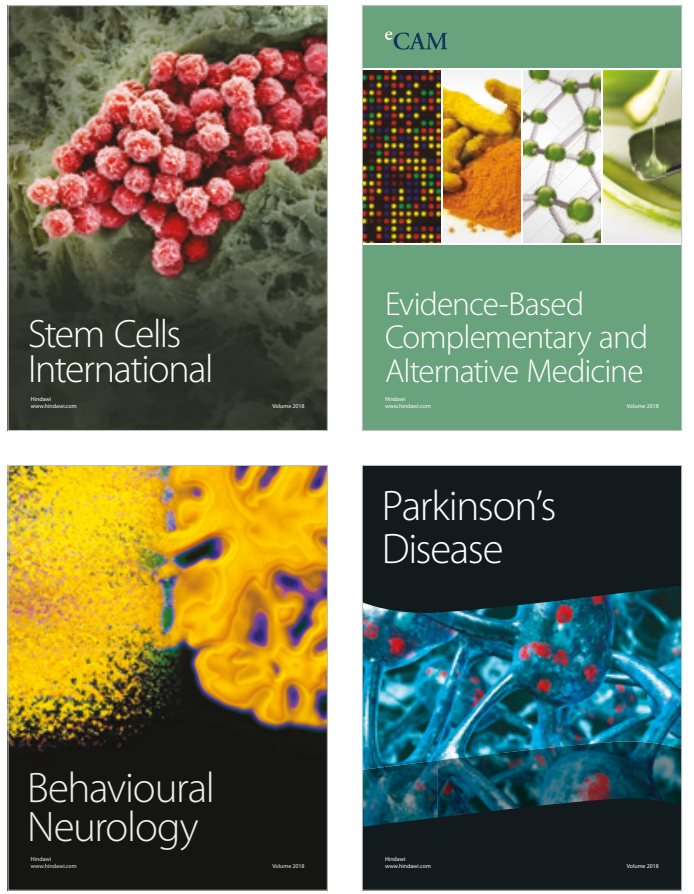

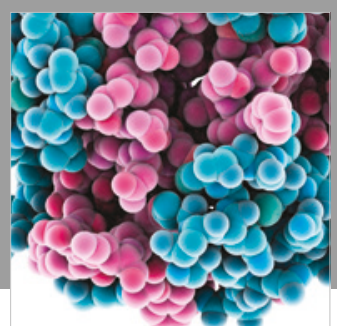

ournal of

Diabetes Research

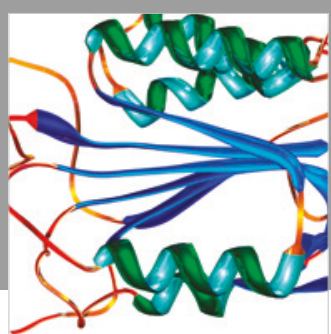

Disease Markers
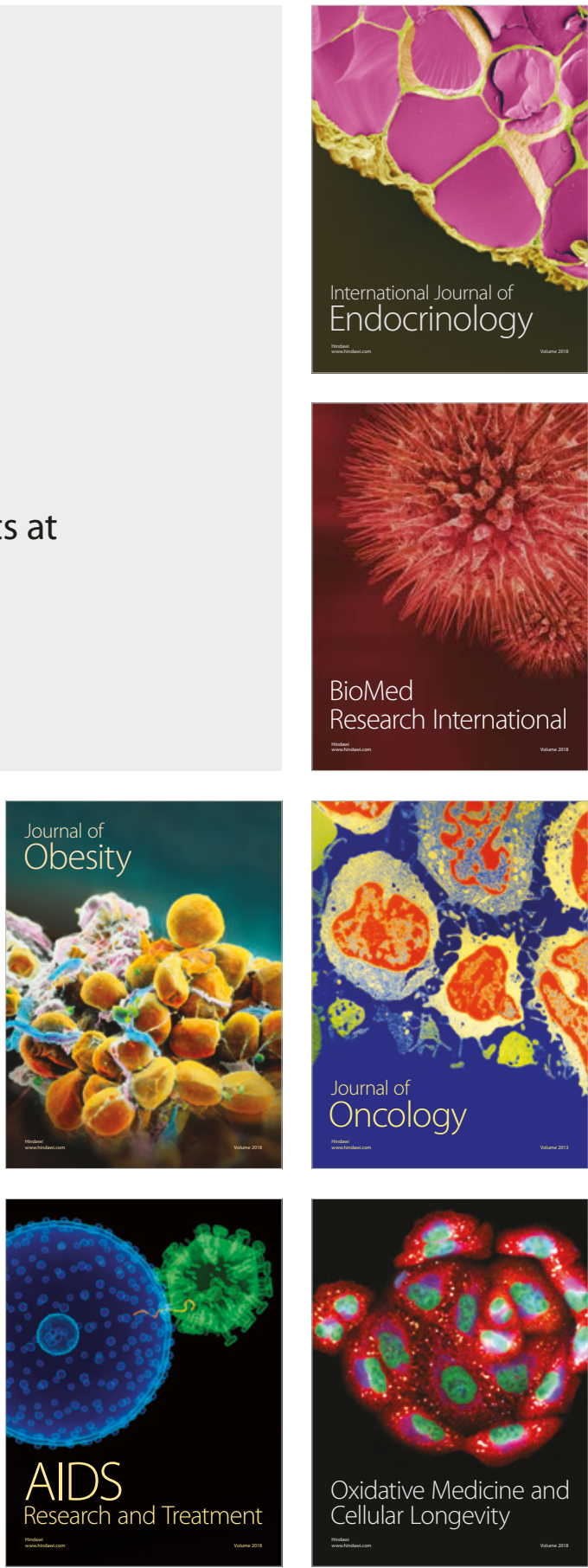